\title{
Pharmacological Stimulation of Locus Coeruleus Reveals a New Antipsychotic-Responsive Pathway for Deficient Sensorimotor Gating
}

\author{
Karen M Alsene' and Vaishali P Bakshi*, I,2 \\ 'Neuroscience Training Program, University of Wisconsin-Madison, Madison, WI, USA and ${ }^{2}$ Department of Psychiatry, University of \\ Wisconsin-Madison, Madison, WI, USA
}

\begin{abstract}
Surprisingly little is known about the modulation of core endophenotypes of psychiatric disease by discrete noradrenergic (NE) circuits. Prepulse inhibition (PPI), the diminution of startle responses when weak prestimuli precede the startling event, is a widely validated translational paradigm for information-processing deficits observed in several mental disorders including schizophrenia, Tourette's syndrome, and post-traumatic stress disorder (PTSD). Despite putative NE disturbances in these illnesses, NE regulation of PPI remains poorly understood. In these studies, regulation of PPI by the locus coeruleus (LC), the primary source of NE to forebrain, was evaluated in rats using well-established protocols to pharmacologically activate/inactivate this nucleus. The ability of drugs that treat deficient PPI in these illnesses to reverse LC-mediated PPI deficits was also tested. Stimulation of LC receptors produced an anatomically and behaviorally specific deficit in PPI that was blocked by clonidine (Cataprese, an $\alpha 2$ receptor agonist that reduces LC neuronal firing after peri-LC delivery), a postsynaptic $\alpha \mid$ NE receptor antagonist (prazosin), and second-generation antipsychotics (olanzapine, seroquel), but not by drugs that antagonized dopamine-I (SCH23390), dopamine-2 (the first-generation antipsychotic Haloperidol), or serotonin-2 receptors (ritanserin). These results indicate a novel substrate in the regulation of PPI and reveal a novel functional role for the LC. Hence, a hyperactive LC-NE system might underlie a deficient sensorimotor gating endophenotype in a subset of patients suffering from psychiatric illnesses including schizophrenia, Tourette's syndrome, and PTSD, and the ability to normalize LC-NE transmission could contribute to the clinical efficacy of certain drugs (Cataprese, prazosin, and second-generation antipsychotics) in these conditions. Neuropsychopharmacology (20II) 36, 1656-1667; doi:I0.1038/npp.20II.47; published online 20 April 20 I I
\end{abstract}

Keywords: catecholamines; startle; locus ceruleus; norepinephrine; Zyprexa; Quetiapine

\section{INTRODUCTION}

Prepulse inhibition (PPI) is a widely used operational measure of sensorimotor gating, a preattentional form of information processing by which organisms defend salient signals from competition by extraneous stimuli (Braff $e t a l$, 2008; Geyer, 2008; Swerdlow et al, 2008). Several psychiatric illnesses involve PPI deficits, which have been proposed as an endophenotype for these conditions (Braff et al, 2008). PPI refers to the diminution of startle responses when the startling stimulus is preceded immediately by a weak prestimulus. This phenomenon permits the use of identical stimulus parameters for testing in humans and animals, making it an excellent translational paradigm with which to study neural substrates underlying the deficits in PPI that

*Correspondence: Dr VP Bakshi, Department of Psychiatry, University of Wisconsin School of Medicine and Public Health, 600I Research Park Boulevard, Madison, WI 53719, USA, Tel: +608 265 6062, Fax: + 608265 3050, E-mail: vbakshi@wisc.edu

Received 27 September 2010; revised 6 March 2011; accepted 6 March 2011 are seen clinically, and in identifying effective medications for illnesses in which sensorimotor gating deficits are presumed a core feature (Geyer, 2008; Swerdlow et al, 2008).

Noradrenergic (NE) transmission is well known to have a role in attention, arousal, vigilance, learning, and working memory (Aston-Jones and Cohen, 2005; Berridge and Waterhouse, 2003; Lapiz and Morilak, 2006; Robbins and Arnsten, 2009; Sara, 2009), yet surprisingly, this system has been almost completely overlooked with regard to PPI. These cognitive constructs theoretically may depend upon intact PPI, and putative dysfunction in NE systems has been hypothesized in numerous mental disorders with demonstrated PPI deficits (Braff et al, 2008; Geyer, 2008; Swerdlow et al, 2008), suggesting that NE may be a crucial modulator of PPI in these patient populations.

Recent studies indicate that systemic manipulations of NE modulate PPI; $\alpha 1$ receptor agonists disrupt PPI in rats and, in mice, deletion of $\alpha 2$ receptors, which can function as presynaptic autoreceptors, reduces PPI and potentiates the PPI-disruptive effects of amphetamine via presumed augmentation of NE release (Alsene et al, 2006; Carasso 
et al, 1998; Kamath et al, 2008; Lahdesmaki et al, 2004; Mishima et al, 2004; Sallinen et al, 1998; Swerdlow et al, 2006). Nevertheless, the specific anatomical substrates of NE regulation of PPI are unknown. The majority of forebrain $\mathrm{NE}$ originates in the locus coeruleus (LC), which regulates attention and cognitive functioning, participates in the maintenance of behavioral states of high arousal and vigilance, and has a key role in stress responses (AstonJones and Cohen, 2005; Berridge and Waterhouse, 2003; Jacobs et al, 1991; Robbins and Arnsten, 2009; Sara, 2009; Valentino et al, 1993). High tonic LC discharge rates correspond to diminished performance in selective-attention tasks (Aston-Jones and Cohen, 2005; Berridge and Waterhouse, 2003; Foote et al, 1980), therefore, a breakdown of intrinsic mechanisms of pre-conscious information filtering (ie, PPI) might also accompany tonic hyperactivity of the LC system. Surprisingly, however, regulation of PPI by LC has not been studied. The present experiments thus examined the role of the LC-NE system in PPI using drug microinfusion protocols that reliably elicit chemical activation or inactivation of LC neurons with concomitant alterations in downstream NE release (Berridge and Abercrombie, 1999; Berridge and Foote, 1991; Berridge et al, 1993).

\section{MATERIALS AND METHODS}

\section{Subjects}

Male Sprague-Dawley rats (300-400 g; Harlan, Madison WI) were housed doubly in a temperature-controlled vivarium $(0700 \mathrm{~h}$, lights on for $12 \mathrm{~h})$ with food and water available ad libitum, and testing from 1000-1500 h. Facilities/procedures were compliant with the NIH guidelines and UW-Madison Institutional Animal Care and Use Committees.

\section{Surgery}

Bilateral indwelling cannulae aimed at the peri-coerulear area or anatomical control sites were implanted stereotaxically as described previously (Alsene et al, 2010) based on Paxinos and Watson (1998). Final coordinates (in mm) were: $\mathrm{AP}=-9.9 ; \quad \mathrm{LM}= \pm 2.85 ; \mathrm{DV}=-4.18 ; 11^{\circ}$ from vertical (peri-LC); $\mathrm{AP}=-9.9 ; \mathrm{LM} \pm 2.3 ; \mathrm{DV}=-3.7$ (dorsolateral control); $\quad \mathrm{AP}=-9.9 ; \quad \mathrm{LM}= \pm 2.4 ; \quad \mathrm{DV}=-4.2$ (ventrolateral control).

\section{Drugs}

Bethanechol chloride (BET), AMPA, clonidine, prazosin hydrochloride, and SCH23390 were from Sigma (St Louis, MO). Ritanserin was from Tocris Bioscience (Ellisville, MO), haloperidol was from Pharmaceutical Associates (Greenville, SC), seroquel was from AstraZeneca (Wilmington, DE), and olanzapine (injectable IM) was from Eli Lilly (Indianapolis, IN). BET (0, 50, $500 \mathrm{ng})$, AMPA (0, 5, $20 \mathrm{ng})$, clonidine $(0,1500 \mathrm{ng})$, and $\mathrm{SCH} 23390(0,0.05 \mathrm{mg} / \mathrm{kg}$, subcutaneously) were dissolved in sterile $(0.9 \%)$ saline. Prazosin (0,1.0 mg/kg, intraperitoneally) was dissolved with sonication in a vehicle of $5 \%$ DMSO in $\mathrm{dH}_{2} \mathrm{O}$. Ritanserin $(0.2 \mathrm{mg} / \mathrm{kg}$, subcutaneously) was dissolved in a vehicle of $95 \%$ isotonic saline, $2.5 \%$ ethanol, and $2.5 \%$ cremaphor
(Fluka Chemicals). Haloperidol $(0,0.01,0.1 \mathrm{mg} / \mathrm{kg}$, intraperitoneally) and seroquel $(0,1.25,2.5,5.0 \mathrm{mg} / \mathrm{kg}$, subcutaneously) were dissolved in isotonic saline with $0.1 \mathrm{~N} \mathrm{HCl}$ at a final $\mathrm{pH}$ of 6.5 . Olanzapine $(0,0.625,1.25,2.5$, $5 \mathrm{mg} / \mathrm{kg}$, intraperitoneally) was diluted with $\mathrm{dH}_{2} \mathrm{O}$. Haloperidol was given $15 \mathrm{~min}$ before testing; all other systemic injections were given $30 \mathrm{~min}$ before testing. Doses were calculated as salts, and systemic injection volume was $1 \mathrm{ml} / \mathrm{kg}$. Doses and injection parameters of antipsychotics and monoamine receptor antagonists previously have been found to antagonize behavioral effects of psychotomimetics, dopamine, or serotonin agonists (Bakshi and Geyer, 1997; Swerdlow et al, 2006; Swerdlow et al, 2008). For microinfusions, injectors (connected via tubing to a microdrive pump) extended $3 \mathrm{~mm}$ past cannulae tips, and delivered drugs at $0.1 \mu \mathrm{l} / \mathrm{min}$ over $2 \mathrm{~min}$, with a 1 -min post-infusion period before reinsertion of stylets and immediate placement of rats into testing chambers.

\section{Startle Chambers and PPI Testing}

Startle chambers (San Diego Instruments, San Diego, CA) contained a non-restrictive Plexiglas cylinder resting inside a ventilated and illuminated sound-attenuating cabinet, with a high-frequency loudspeaker producing acoustic stimuli. Whole-body startle responses caused vibrations that were converted into analog signals by a piezoelectric unit attached to the platform (Mansbach et al, 1988), and were digitized and stored by a microcomputer and interface unit. Monthly calibrations were performed using the $\mathrm{dB}(\mathrm{A})$ scale to ensure accuracy of the equipment.

The test session had a 5-min, 65-dB background noise (remaining on for the entire session) followed by presentation (in a pseudorandom order) of 12 Pulse-Alone trials (40-ms, 120-dB broadband bursts), Prepulse + Pulse trials (20-ms noises 3,9 , or $15 \mathrm{~dB}$ above the background noise and presented $100 \mathrm{~ms}$ before the onset of the Pulse; six presentations of each), and four No-Stimulus trials. Four Pulse-Alone trials were also presented at the beginning and the end of the session to ensure that startle magnitude was stable during the portion of the session when PPI was measured, as the most rapid habituation of the startle response occurs within the first several presentations (Geyer et al, 1990); these Pulse-Alone trials were excluded from the calculations of startle and \%PPI. The duration of this test session was designed specifically to match the timeframe during which it has been reported that pharmacological stimulation of LC activates these neurons and causes NE release in terminal fields (Berridge and Abercrombie, 1999; Pudovkina et al, 2002; Van Gaalen et al, 1997). During the week before drug testing, all rats underwent one exposure/ day on three separate days to this session with sham infusions preceding the last test to familiarize rats with the testing and microinfusion procedures.

\section{Behavioral Observation Cages}

Rats were habituated to test cages (clear polycarbonate, $9.5^{\prime} \times 17^{\prime} \times 8^{\prime}$, wire-grid floors; each rat had his own dedicated cage) for several days before the experiment. On test days, the frequency and duration of locomotion (cage crossings), rearing, feeding, drinking, and grooming 
was rated in situ for $30 \mathrm{~min}$ by an experimenter blind to treatment.

\section{Histology}

After experiments, rats were perfused transcardially with $10 \%$ formalin (Sigma), $60-\mu \mathrm{m}$ sections were taken and stained with cresyl violet, and placements were verified by an experimenter blind to behavioral data; rats with missed peri-LC placements were excluded from subsequent analyses of LC data, but were analyzed as a separate group to provide an additional anatomical control site for peri-LC infusions (Figure 1e).

\section{Data Analysis}

The startle response was recorded for $100 \mathrm{~ms}$ from the onset of the 120-dB burst for each Pulse-Alone and Prepulse + Pulse trial. Two measurements were calculated from these values for each rat for each of the different treatment conditions: Startle magnitude was the average of all Pulse-
Alone trials; PPI was a percent score for each Prepulse + Pulse trial type: \%PPI $=100-\{[$ (startle response for Prepulse + Pulse trial)/(startle response for Pulse-Alone trial)] $\times$ $100\}$. Startle data were analyzed with 1- or 2-factor ANOVAs (pretreatment $\times$ treatment); \%PPI had prepulse intensity as an additional ANOVA factor, and Newman-Keuls post-hocs were carried out with alpha level for significance at 0.05 .

\section{Experimental Design}

Unless noted otherwise, each experiment used experimentally naïve rats in a within-subjects design, with each rat receiving all drug combinations in a counterbalanced order, with at least 2 days separating consecutive tests.

Study 1. Does pharmacological activation of LC disrupt PPI? Rats received the muscarinic cholinergic agonist BET $(0,50,500 \mathrm{ng} ; N=9)$ or the glutamate receptor agonist AMPA $(0,5,20 \mathrm{ng})$ into peri-LC immediately before testing in startle chambers. The different AMPA doses were tested

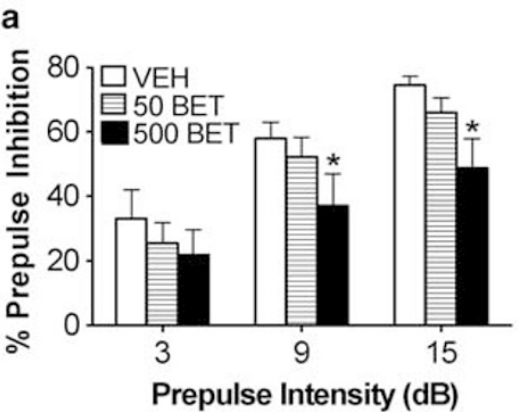

c

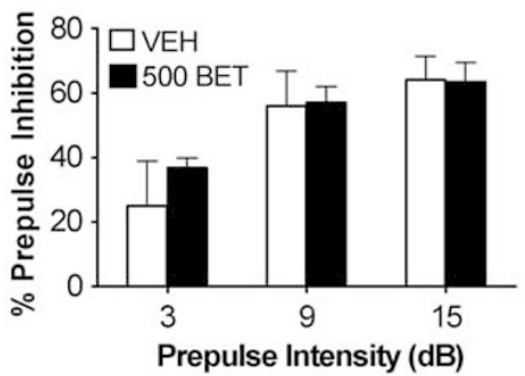

b

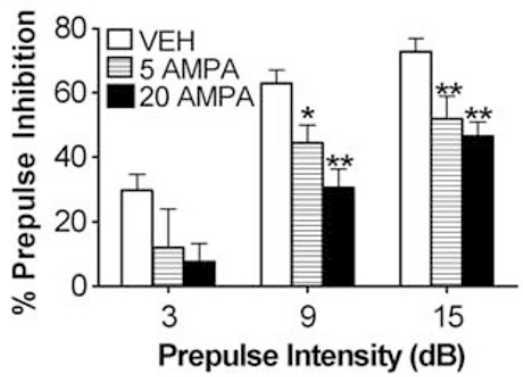

d

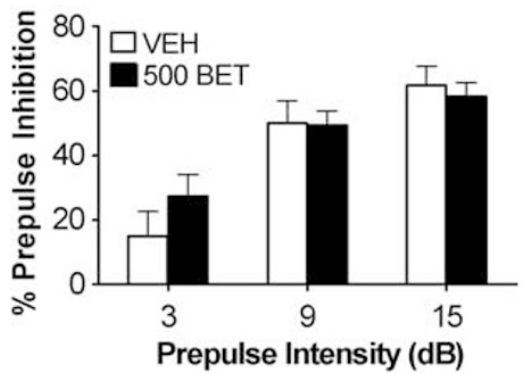

e

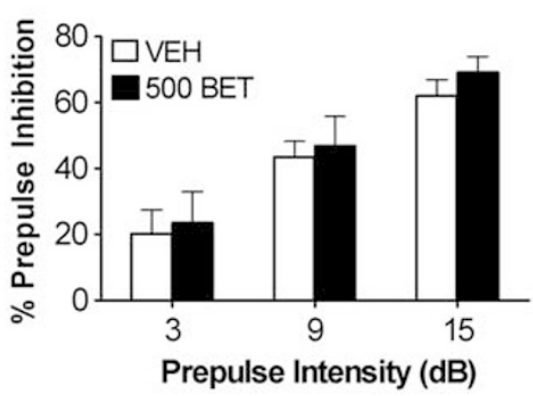

Figure I Anatomically selective stimulation of locus coeruleus disrupts PPI. \% Prepulse inhition (PPI) (mean \pm SEM for each prepulse intensity, which is in $\mathrm{dB}$ above background noise level) for rats receiving peri-LC (a) bethanechol (BET), or (b) AMPA. BET and AMPA in peri-LC reduced PPI. Separate rats received BET in control sites (c) dorsolateral, (d) ventrolateral, or (e) anterior to the LC, but these infusions did not alter PPI. Doses are in $\mathrm{ng} / 200 \mathrm{nl}$, $\mathrm{VEH}=$ vehicle. $* P<0.05, * * P<0.01$, relative to vehicle. 
in separate groups of rats (low dose $N=10$, high dose $N=11$ ) to avoid repeated peri-LC AMPA infusions, which can cause lesions. Each group of rats also was treated with vehicle so that there was a drug-free control condition for each AMPA dose.

Study 2. Are PPI effects anatomically specific to LC? We determined whether infusion of BET into regions neighboring the peri-LC would disrupt PPI. Rats received vehicle and the highest dose of BET into either a dorsolateral $(N=6)$ or a ventrolateral $(N=12)$ control site before startle testing. For these and subsequent experiments, BET was used because it produces sustained and reversible LC neuronal activation and downstream NE release following peri-LC delivery without neurotoxicity (Berridge and Foote, 1991).

Study 3. Are LC-mediated PPI deficits secondary to generalized motor activation? PPI and several exploratory and ingestive behaviors were tested (in the same rats, but on separate test days) following peri-LC BET infusion. The behavioral scoring for exploratory/ingestive behaviors was conducted for $30 \mathrm{~min}$ (broken into three 10-min segments) to parallel the timeline of the PPI test. Thus, rats $(N=10)$ received vehicle or BET ( $500 \mathrm{ng}$ ) into peri-LC, and were tested immediately after infusions for PPI or in behavioral observation cages (see above). This protocol was repeated over three additional test days in a within-subjects design with order of drug treatments and testing paradigm counterbalanced, so that each rat underwent each treatment (vehicle or BET) in each paradigm (PPI or behavioral observation).

Study 4. Are LC-mediated PPI deficits specific to NE transmission? First, to confirm that the peri-LC BET effect was due to activation of LC neurons, we determined whether co-infusion of clonidine, an $\alpha 2 \mathrm{NE}$ (autoreceptor) agonist that significantly reduces activity of LC neurons and $\mathrm{NE}$ release in terminal regions after peri-LC delivery in anesthetized or awake rats (Berridge et al, 1993; Pudovkina et al, 2002; Pudovkina et al, 2001; Van Gaalen et al, 1997), prevented the peri-LC BET-induced PPI deficit. Thus, rats $(N=7)$ received a 'cocktail' of clonidine $(0$ or $1500 \mathrm{ng})$ and BET (0 or $500 \mathrm{ng}$ ) into peri-LC immediately before startle/ PPI testing; each rat received all the four drug combinations in a counterbalanced order over four test days. Second, to determine whether downstream activation of NE, DA, or 5-HT transmission mediates LC-induced PPI deficits, separate groups of rats were given systemic injections of postsynaptic receptor antagonists for either the $\alpha 1 \mathrm{NE}$ receptor (prazosin, 0 or $1 \mathrm{mg} / \mathrm{kg} ; N=11$ ), the $\mathrm{D} 1$ receptor (SCH23390, 0 or $0.05 \mathrm{mg} / \mathrm{kg} ; N=8$ ), the D2 receptor (haloperidol, 0 or $0.1 \mathrm{mg} / \mathrm{kg} ; \quad N=11$ ), or the 5 -HT2 receptor (ritanserin, 0 or $2 \mathrm{mg} / \mathrm{kg} ; N=7$ ) before receiving peri-LC BET infusions (0 or $500 \mathrm{ng}$ ) and PPI testing.

Study 5. Are LC stimulation-induced PPI deficits reversed by antipsychotics? Separate groups of rats were pretreated with either seroquel ( 0 or $1.25 \mathrm{mg} / \mathrm{kg}, N=11$ ) or olanzapine ( 0 or $0.625 \mathrm{mg} / \mathrm{kg}, N=8$ ), or haloperidol $(0$ or $0.01 \mathrm{mg} / \mathrm{kg}$, $N=7)$ before receiving peri-LC infusions of BET $(0,500 \mathrm{ng})$ and being tested in startle chambers. Note that multiple additional doses of each drug were also tested in separate groups of rats, however, because no significant effects on LC-mediated PPI deficits were seen with these doses, these data are not presented for brevity.

\section{RESULTS}

\section{Stimulation of LC Receptors Disrupts PPI}

Figures $1 \mathrm{a}$ and $\mathrm{b}$ show that both BET and AMPA disrupted PPI, as indicated by main effects of BET $(\mathrm{F}(2,16)=4.5$, $P<0.03)$ or AMPA $(20-n g$ dose: $(\mathrm{F}(1,10)=5.9, P<0.04)$; 5-ng dose: $(\mathrm{F}(1,9)=11.0, P<0.01))$ on \%PPI. Because vehicle values for the two AMPA doses did not differ, they are combined with all AMPA data in one graph for the sake of simplicity. Post-hoc tests revealed significant decreases in $\%$ PPI by the $500-n g$ dose of BET $(P<0.05)$ or either AMPA dose $(P<0.05-P<0.01)$ at the 9 - and $15-\mathrm{dB}$ prepulse intensities. Thus, multiple manipulations that activate the LC (Berridge and Foote, 1991) significantly disrupted PPI.

\section{PPI Deficits are Due to Selective Actions within the LC}

The same doses and infusion parameters of BET that caused significant PPI disruption after peri-LC administration failed to alter PPI in sites $250-800 \mu \mathrm{m}$ dorso- or ventrolateral or anterior to the LC, indicating that PPI deficits after peri-LC infusion were not due to diffusion of the drugs to other sites, but rather were caused by specific actions within the LC (Figures 1c-e and Figure 2).

\section{Pharmacological Activation of LC Decreases PPI without Producing Nonspecific Behavioral Deficits}

Peri-LC infusion of BET (500 ng) once again disrupted PPI (Figure 3a), as indicated by the significant main effect of drug treatment $(\mathrm{F}(1,9)=8.8, P<0.02)$, and post-hoc analyses revealing a significant decrease in percent PPI by BET at the $9-(P<0.05)$ and $15-\mathrm{dB}(P<0.01)$ prepulse intensities. In contrast, unconditioned exploratory and ingestive behaviors were unaltered (Figures 3b-f; all drug treatment F-ratios $<0.81$ and $P$-values $>0.37$ ), suggesting that LC stimulation produces a reduction specifically in sensorimotor gating that does not arise secondarily from a global behavioral disruption.

\section{PPI Effects are Independent of Changes in Baseline Startle}

Startle magnitude (response to the Pulse-alone trials) was analyzed to determine the extent to which alterations in PPI were associated with changes in baseline startle (Table 1). No effects on startle were seen with any drugs but BET, which produced a small but statistically significant decrease in startle in some experiments. Although it seemed unlikely that BET-induced PPI deficits could be due simply to alterations in baseline startle (as in several experiments, BET disrupted PPI without changing startle values), we performed linear regression analyses on startle and composite \%PPI scores (average \%PPI across all prepulse intensities) from all BET experiments to confirm that BETinduced PPI deficits were independent from changes in startle. There was no correlation between startle and PPI values under either vehicle or BET treatment ( $P$-values $\geqslant 0.1$, and $R^{2}$ values $\leqslant 0.028$ ) (Figure 4 ). Thus, LC stimulation produces deficits in PPI that are not artifacts of generalized changes in startle reactivity. 

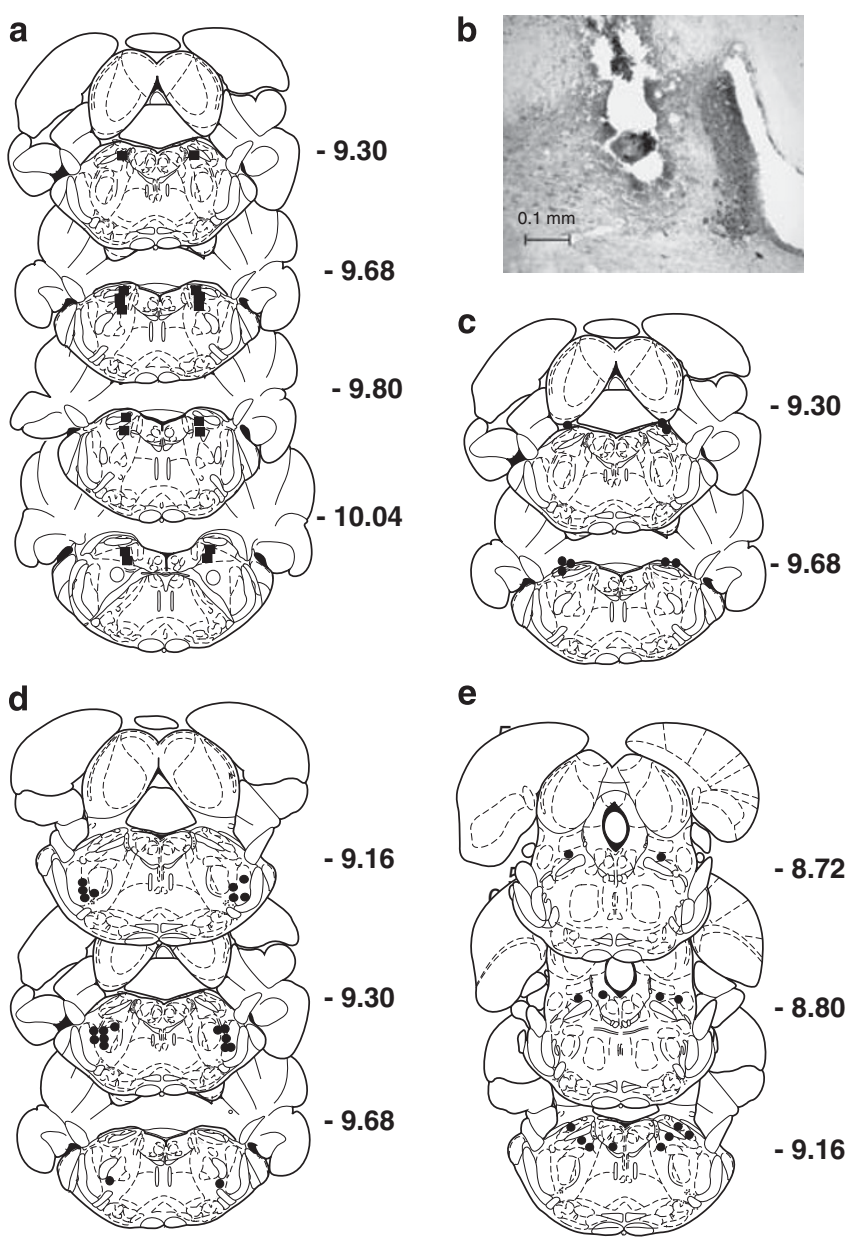

Figure 2 Injector tip placements within (a) peri-LC, and (b) photomicrograph of a representative peri-LC placement. Locations of injector tips where BET infusion failed to disrupt \%PPI in regions (c) dorsolateral, (d) ventrolateral, and (e) anterior to LC (corresponding to PPI data in Figures $\mathrm{Ic}-\mathrm{e}$ ). Distances (in $\mathrm{mm}$ ) are posterior to bregma.

\section{Manipulations that Reduce NE Transmission Reverse LC-Mediated PPI Deficits}

For these experiments, PPI was measured as above, but because no significant interactions were observed with the prepulse intensity factor, PPI data are presented as a composite PPI score, which represents \%PPI averaged across all three prepulse intensities. A significant interaction was seen between $\mathrm{BET}$ and clonidine treatments $(\mathrm{F}(1,6)=12.5, P<0.013)$, with BET-alone markedly reducing PPI $(P<0.05)$ and clonidine restoring PPI to control levels when rats were given clonidine and BET simultaneously into peri-LC $(P<0.05)$. Thus, reducing the activity of LC neurons with clonidine prevented the BET-induced PPI deficit (Figure 5a). In the prazosin experiment, significant main effects of BET $(\mathrm{F}(1,10)=6.2, P<0.03)$ and prazosin $(\mathrm{F}(1,10)=5.3, P<0.04)$, and, importantly, a significant interaction between BET and prazosin $(\mathrm{F}(1,10)=6.0, P<0.03)$ were seen, indicating that the $\mathrm{NE}$ receptor antagonist blocked LC-mediated PPI deficits. Posthoc tests confirmed that PPI levels in the prazosin-BET condition were significantly higher than those for the vehicle-BET condition $(P<0.05)$, and were indistinguish- able from those of the vehicle-vehicle condition. Thus, pretreating rats with a postsynaptic NE receptor antagonist totally abolishes the PPI deficit caused by stimulation of the LC.

One might expect under the proper conditions that selective NE reuptake inhibitors would reduce PPI, and there is some evidence to suggest this possibility (Oranje et al, 2004; Phillips et al, 2000; Quednow et al, 2004). In general, relatively few studies have examined the effects of this class of drugs on PPI, and the results are equivocal; whether or not selective NE reuptake inhibitors disrupt PPI or even increase it depends greatly on the drug used, the dose range, and the parameters of testing (Gould et al, 2005; Oranje et al, 2004; Phillips et al, 2000; Pouzet et al, 2005; Quednow et al, 2004). It should be noted that this inconsistent profile is also seen with serotonin-selective reuptake inhibitors, which have similarly mixed effects on PPI, despite the parallel finding that 5-HT releasers and direct receptor agonists reliably and potently disrupt PPI (reviewed in Geyer et al, (2001)). Because reuptake inhibitors are activity-dependent (as opposed to monoamine releasers, which markedly augment synaptic transmitter levels, regardless of neuronal firing), it may be that the level of synaptic NE produced by them is not sufficient to always reliably disrupt PPI. The present findings indicate that when NE projections from the LC are stimulated directly, however, a strong and reliable PPI disruption is produced.

\section{LC-mediated PPI Disruption is Independent of DA or 5-HT2 Receptors}

As above, composite \%PPI scores are presented for the sake of brevity. In each of the three experiments, there was a significant main effect of BET treatment: D1 antagonist experiment $(\mathrm{F}(1,7)=8.7, P<0.02)$; D2 antagonist experiment $(\mathrm{F}(1,10)=20.6, P<0.002)$; 5-HT antagonist experiment $(\mathrm{F}(1,6)=8.8, P<0.024)$. Post-hoc analyses indicated that in each case, BET significantly reduced PPI $(P<0.05)$ (Figure 5a). No pretreatment main effects or pretreatment $x$ treatment interactions were seen for the DA or 5-HT2 receptor antagonists. Thus, unlike blockade of NE $\alpha 1$ receptors, antagonism of D1, D2, or 5-HT2 receptors does not reverse PPI deficits produced by stimulation of the LC. Note that a similar failure to reverse LC BET-induced PPI deficits was found in a separate experiment $(N=5)$ with the 5-HT1A antagonist WAY100635 $(0.1 \mathrm{mg} / \mathrm{kg})$ : \%PPI values were $\quad \mathrm{VEH} / \mathrm{VEH}=59 \pm 6 ; \quad \mathrm{VEH} / \mathrm{BET}=39 \pm 4 ; \quad \mathrm{WAY} /$ $\mathrm{VEH}=44 \pm 5 ; \mathrm{WAY} / \mathrm{BET}=42 \pm 6$. However, because a profound (approximately 50\%) reduction in startle (main effect of WAY $(F(1,4)=9.4, P<0.04))$ ) was produced by WAY that tended to cause this drug to reduce PPI on its own (see above), these data are less clear to interpret. Nevertheless, the uncompromised failure of D1, D2, and 5-HT2 antagonists to reverse the BET-mediated PPI deficits strongly indicates that DA and 5-HT transmission are not indirectly responsible for the LC-mediated PPI effect.

To confirm that these doses of SCH23390 $(0.05 \mathrm{mg} / \mathrm{kg})$, haloperidol $(0.1 \mathrm{mg} / \mathrm{kg})$, and ritanserin $(2 \mathrm{mg} / \mathrm{kg})$ were sufficiently high to normalize deficient PPI in this specific test session, additional experiments were conducted to determine whether PPI deficits induced by the DA agonist 
a

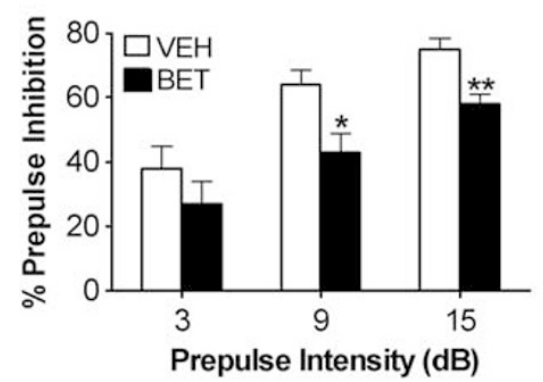

c
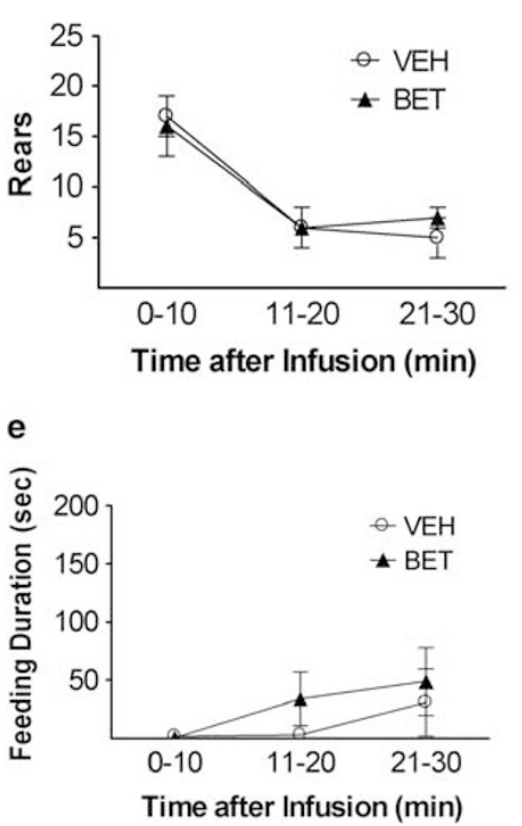

b

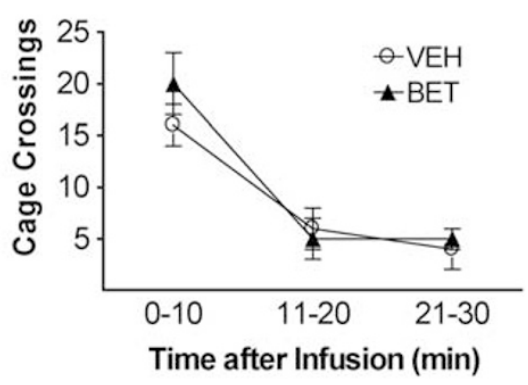

d
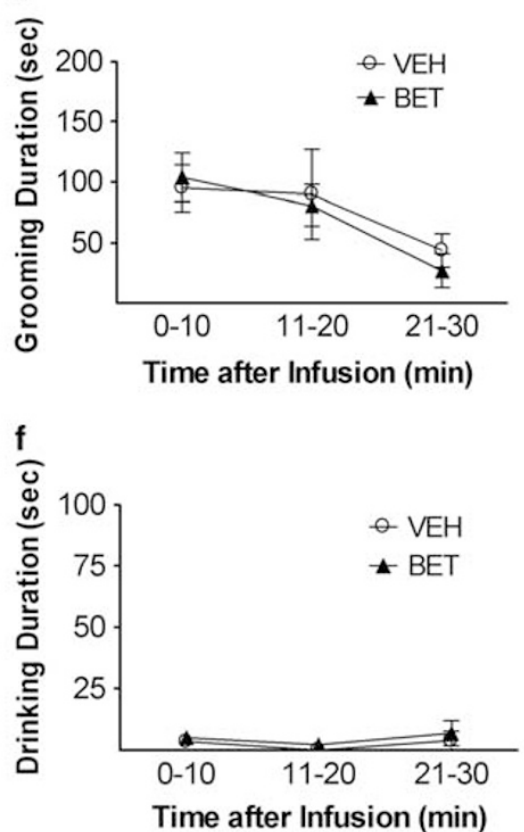

Figure 3 PPI deficit caused by peri-LC BET is behaviorally specific. Effects of peri-LC bethanechol (BET, $500 \mathrm{ng} / 200 \mathrm{nl}$ ) on (a) \%PPI across multiple prepulse intensities, which are in $\mathrm{dB}$ above background noise level, (b) locomotor activity, (c) rearing, (d) grooming, (e) feeding, and ( $\mathrm{f}$ ) drinking. Values represent means \pm SEM for each treatment. $* P<0.05$, relative to vehicle $(V E H)$. BET in peri-LC disrupted PPI without altering other behaviors.

apomorphine (APO, $0.5 \mathrm{mg} / \mathrm{kg}$ ) or the 5 -HT2 agonist DOI $(0.3 \mathrm{mg} / \mathrm{kg})$ could, respectively, be reversed by these drugs. It was found that APO $(P<0.01)$ and DOI $(P<0.01)$ significantly reduced $P P I$ (vehicle values $=69 \pm 3$; $\mathrm{APO}=34 \pm 10 ; \quad \mathrm{DOI}=48 \pm 5)$, that the SCH23390/APO $(60 \pm 7)$ and haloperidol/APO $(59 \pm 8)$ values were significantly higher than those for the vehicle/APO condition $(P<0.05)$, and that the ritanserin/DOI condition $(68 \pm 5)$ was significantly higher than the vehicle/DOI $(P<0.05)$. These results agree with previous reports indicating that the presently used doses are sufficiently high to normalize PPI deficits produced by DA or 5-HT agonists, and further confirm that the failure of DA and 5-HT receptor antagonists to reverse LC-mediated PPI deficits is not just due to underdosing with these compounds (Bakshi and Geyer, 1997; Swerdlow et al, 2006).

\section{LC-mediated PPI Deficits are Blocked by Second- Generation Antipsychotics}

BET infusion disrupted PPI in all experiments (Figure 5b), evidenced by the main effect of treatment in each: olanzapine experiment $(\mathrm{F}(1,7)=6.4, P<0.039)$; seroquel experiment $(\mathrm{F}(1,10)=8.1, P<0.02)$; haloperidol experiment $(\mathrm{F}(1,7)=11.3, \quad P<0.01)$, and subsequent post-hoc tests $(P<0.05$ vs the vehicle + vehicle condition $)$. Importantly, pretreatment with the atypical antipsychotics prevented these BET-induced PPI deficits, as indicated by the significant pretreatment $\times$ treatment interactions for olanzapine $(\mathrm{F}(1,7)=11.9, P<0.01)$ and seroquel $(\mathrm{F}(1,10)=4.5$, $P<0.05)$, but pretreatment with haloperidol was ineffective. Post-hoc tests revealed that the $0.625-\mathrm{mg}$ dose of olanzapine $(P<0.05)$ and the $1.25-\mathrm{mg}$ dose of seroquel $(P<0.01)$ completely reversed the PPI deficit induced by peri-LC BET, without altering PPI on their own. Thus, regardless of dose, haloperidol failed to affect PPI deficits induced by LC stimulation, whereas seroquel and olanzapine restored PPI to normal levels. Interestingly, the doses of seroquel and olanzapine that reversed LC-mediated PPI deficits are approximately 10-fold lower than those required to antagonize PPI deficits induced by drugs such as amphetamine (Bakshi and Geyer, 1995; Swerdlow et al, 1996).

Because olanzapine shows activity at muscarinic receptors (Schotte et al, 1996), it is conceivable that reversal of BET-induced PPI deficits may occur via direct blockade 
Table I Effects on Baseline Startle Magnitude (mean \pm SEM Responses to Pulse-Alone)

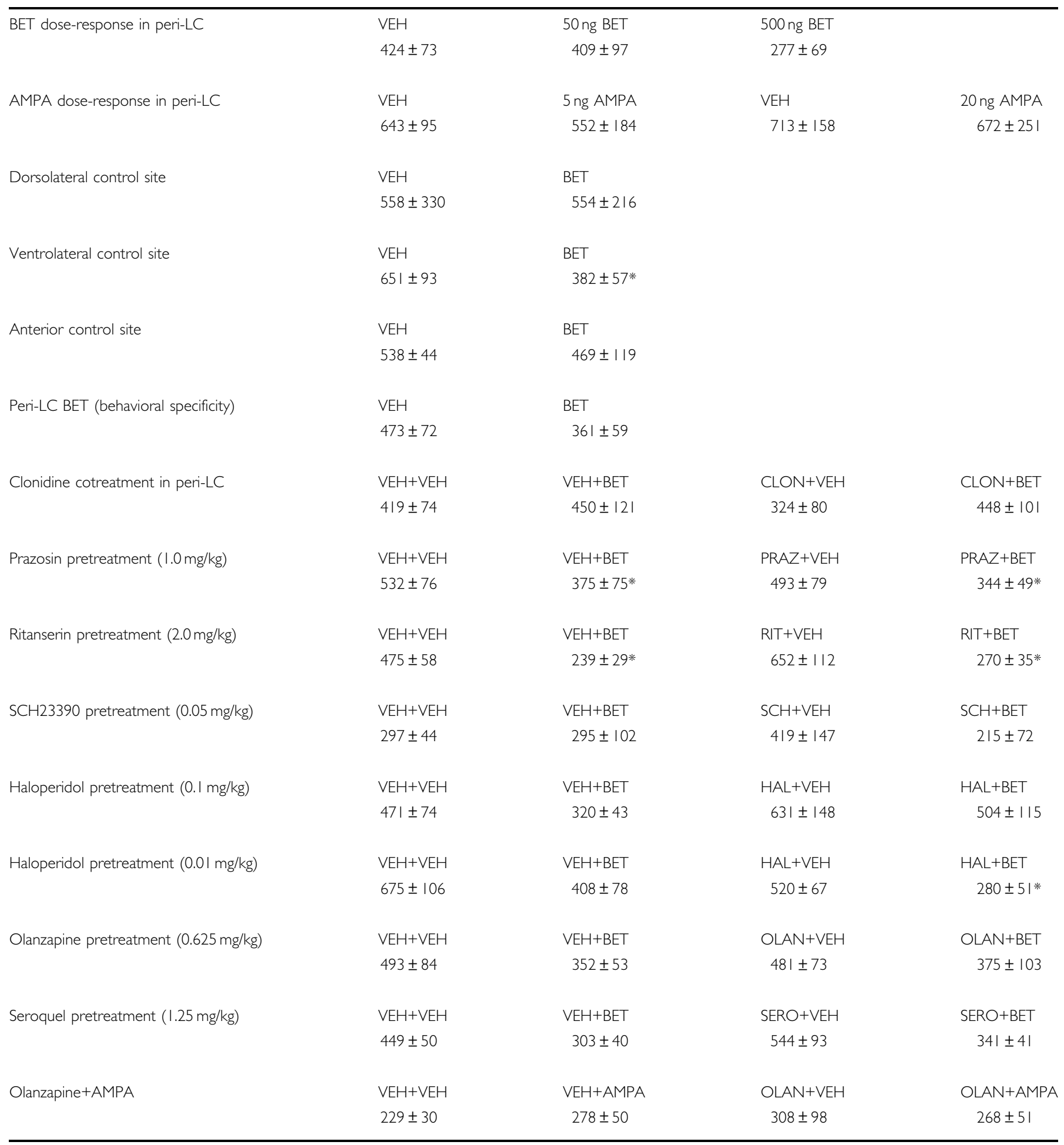

Abbreviations: BET, bethanechol (500 ng/200 nl unless indicated otherwise); CLON, clonidine ( 1500 ng/200 nl); HAL, haloperidol; OLAN, olanzapine; PRAZ, prazosin; RIT, ritanserin; SCH, SCH23390; SERO, seroquel; VEH, vehicle.

$* P<0.05$, compared with $\mathrm{VEH}$ or $\mathrm{VEH}+\mathrm{VEH}$.

of BET at the level of the LC muscarinic receptor. An additional experiment was performed to test this possibility. Experimentally naïve rats $(N=8)$ received olanzapine $(0,0.625 \mathrm{mg} / \mathrm{kg})$ before peri-LC AMPA $(0$, $20 \mathrm{ng}$ ) before startle/PPI testing, in a counterbalanced within-subjects design over four test days. It was reasoned that if olanzapine blocked peri-LC AMPA-induced PPI deficits, this effect could not occur at the level of a common LC receptor because AMPA has no appreciable affinity for muscarinic receptors and olanzapine does not have 
a

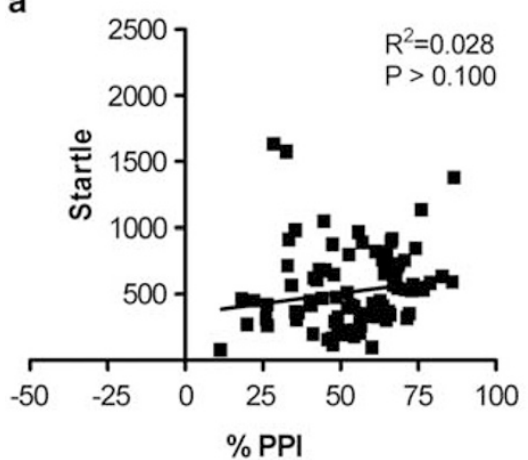

b

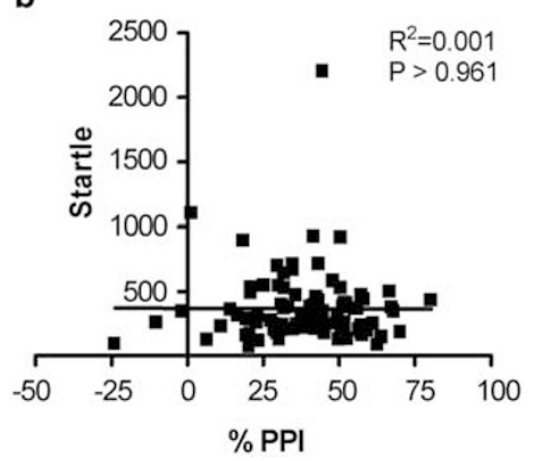

Figure 4 Linear regression analysis of startle and \%PPI values (composite PPI score collapsed across prepulse intensities) for individual subjects from all experiments with infusion of (a) vehicle or (b) bethanechol $(500 \mathrm{ng} / 200 \mathrm{nl})$. No significant correlation between startle and prepulse inhibition values was seen under each treatment condition, indicating that PPI scores were independent of baseline startle responses across all bethanechol experiments.

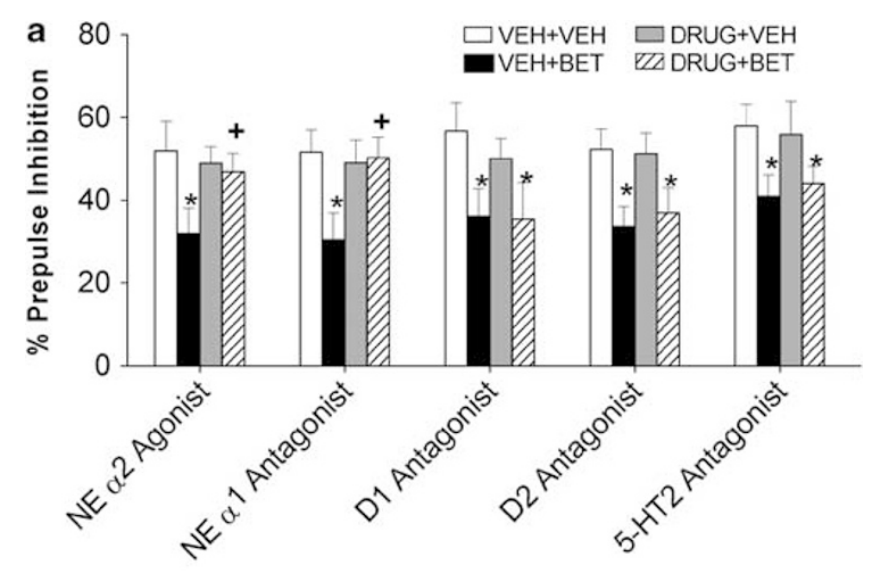

b

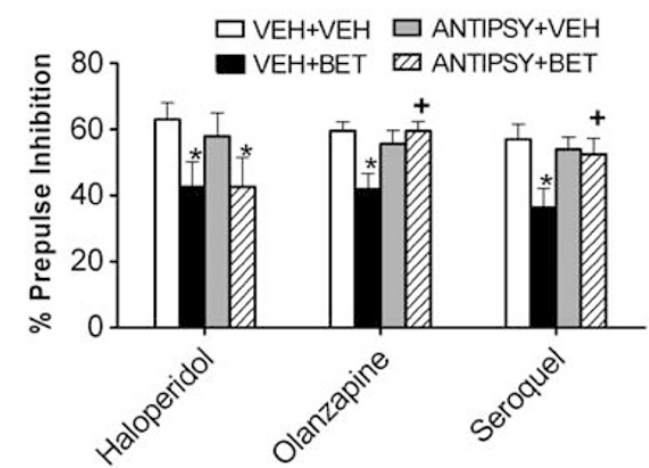

Figure 5 LC-mediated PPI deficits are independent of D2 and 5-HT2 receptors but are reversed by atypical antipsychotics. \%PPI (mean \pm SEM of composite PPI score collapsed across prepulse intensities) with peri-LC vehicle (VEH) or bethanechol (BET, $500 \mathrm{ng} / 200 \mathrm{nl}$ ) after injection with (a) antagonists for postsynaptic NE receptors (prazosin, $1 \mathrm{mg} / \mathrm{kg}$ ), DI receptors $(\mathrm{SCH} 23390,0.05 \mathrm{mg} / \mathrm{kg}$ ), D2 receptors (haloperidol, $0.1 \mathrm{mg} /$ $\mathrm{kg}$ ), 5-HT2 receptors (ritanserin, $2 \mathrm{mg} / \mathrm{kg}$ ), or a peri-LC $\alpha 2$ receptor agonist (clonidine, $1500 \mathrm{ng} / 200 \mathrm{nl}$ ). Clonidine and prazosin, but not DA or 5-HT2 antagonists, reversed BET-induced PPI disruption, indicating that release of $\mathrm{NE}$, but not DA or $5-\mathrm{HT}$, mediates this LC-induced effect. Peri-LC BETinduced PPI deficits after injection of (b) atypical antipsychotics olanzapine $(0.625 \mathrm{mg} / \mathrm{kg})$ or seroquel $(1.25 \mathrm{mg} / \mathrm{kg})$, or the traditional neuroleptic haloperidol $(0.01 \mathrm{mg} / \mathrm{kg})$. Only the atypical antipsychotics blocked BETinduced PPI deficits. ${ }^{*} P<0.05$, ${ }^{*} * P<0.01$, relative to $\vee E H+V E H$. $P<0.05,{ }^{+} P<0.0$ I, relative to $\mathrm{VEH}+\mathrm{BET}$.

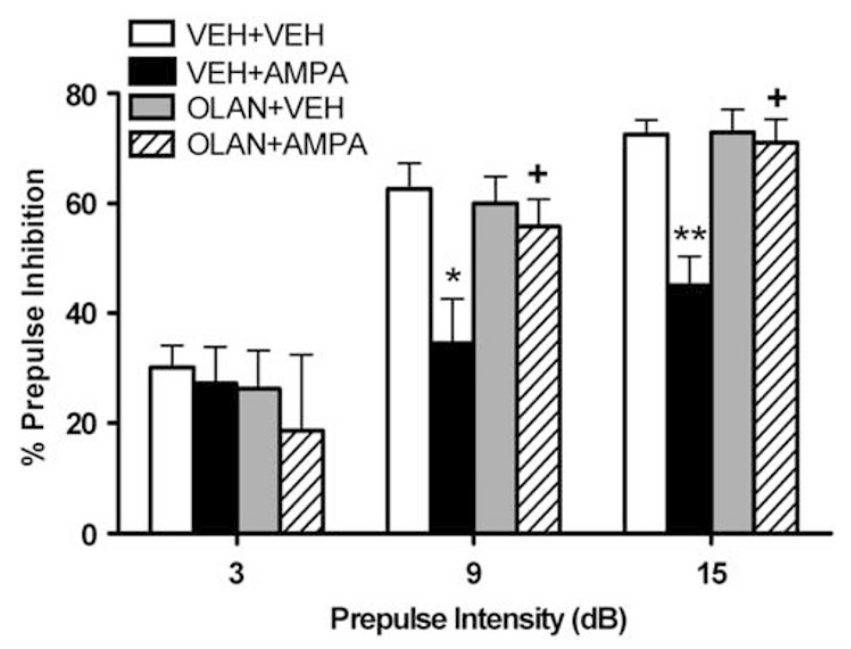

Figure $6 \% \mathrm{PPI}$ (mean \pm SEM for each prepulse intensity, which is in $\mathrm{dB}$ above background noise level) for rats receiving peri-LC AMPA (20 ng/ $200 \mathrm{nl}$ ) after pretreatment with the atypical antipsychotic olanzapine (OLAN, $0.625 \mathrm{mg} / \mathrm{kg}$ ). AMPA reduced PPI and OLAN normalized this deficit. ${ }^{*} P<0.05$, ${ }^{*} * P<0.0$ I, relative to $\mathrm{VEH}+\mathrm{VEH} .{ }^{+} P<0.05$, relative to $\mathrm{VEH}+\mathrm{AMPA}$.

appreciable affinity for AMPA receptors (Bymaster et al, 1999). Figure 6 shows that olanzapine did reverse AMPAmediated PPI deficits at multiple prepulse intensities, as indicated by the significant interaction between pretreatment $\times$ treatment $\times$ prepulse $\quad(\mathrm{F}(2,14)=4.7, \quad P<0.027)$. AMPA significantly reduced PPI at the $9-(P<0.05)$ and $15-\mathrm{dB}(P<0.01)$ prepulse intensities, and olanzapine pretreatment almost completely abolished these effects $(P<0.05)$. Hence, the most parsimonious conclusion is that olanzapine blocks the downstream post-synaptic effects of LC-induced NE release.

\section{DISCUSSION}

It was demonstrated for the first time that stimulation of LC cholinergic or glutamatergic receptors disrupts PPI in an 
anatomically, behaviorally, and neurochemically specific manner, consistent with previous reports that such manipulations activate LC neuronal firing and elevate NE release in LC terminal regions (Berridge and Abercrombie, 1999; Berridge and Foote, 1991; Pudovkina et al, 2002; Van Gaalen et al, 1997). These disruptions likely result from specific actions within the LC, because infusions of BET even $250 \mu \mathrm{m}$ away from the active drug zone had no effect, co-infusion of the $\alpha 2$ autoreceptor agonist clonidine (which reliably and markedly reduces activity of LC neurons and downstream NE release including in unanesthetized rats (Berridge et al, 1993; Pudovkina et al, 2002; Pudovkina et al, 2001; Van Gaalen et al, 1997)) prevented the BET-induced deficit, and systemic administration of the $\alpha 1 \mathrm{NE}$ antagonist prazosin completely reversed the PPI deficit following periLC BET. The same manipulation that disrupted PPI failed to alter locomotion, grooming, rearing, or ingestive behaviors, indicating that LC-mediated PPI disruption is not the nonspecific consequence of generalized motor effects. Finally, multiple second-generation antipsychotics blocked LC-induced deficits in PPI, and these effects were found to be independent of DA or 5-HT receptors. Taken together, these results implicate a new pathway in the regulation of sensorimotor gating, provide evidence for a novel functional role for LC in cognitive processes, and suggest a novel mechanism to explain the particular efficacy of certain antipsychotics and NE-blocking drugs in several psychiatric disorders in which decreased PPI is a core endophenotype.

In rats, the higher drug concentrations achieved with repeated intravenous delivery or chronic administration of atypical antipsychotics actually increase several functional measures of LC cell firing (Dawe et al, 2001; Ramirez and Wang, 1986), which may be why higher doses of olanzapine and seroquel failed to reverse the LC-mediated deficit in PPI. In contrast, low doses like the ones that reversed PPI deficits in the present studies do not consistently affect LC firing, but do potently antagonize post-synaptic NE receptors (Bymaster et al, 1996; Dawe et al, 2001; Svensson, 2003). Thus, certain antipsychotics may normalize LCinduced deficits in PPI by blocking NE receptor activation (likely $\alpha 1$ ) in LC terminal regions that is caused by downstream release of NE as a result of (BET-induced) LC activation (Berridge and Foote, 1991). The present findings also are consistent with previous reports showing that direct stimulation of $\alpha 1 \mathrm{NE}$ receptors with cirazoline disrupts PPI (Alsene et al, 2006; Carasso et al, 1998), but significantly expand these results by revealing for the first time a putative endogenous pathway responsible for NE-mediated PPI disruptions.

Dopamine and serotonin antagonists in behaviorally active dose ranges (Bakshi and Geyer, 1997; Swerdlow et al, 2006) failed to alter LC-mediated PPI disruption, suggesting that transsynaptic activation of D1, D2, or 5-HT2 receptors does not underlie the present effects. This finding is noteworthy because to date, a majority of studies into the neural substrates of PPI have focused on DA- and 5-HTbased manipulations (Geyer, 2008). Thus, the current results suggest the exciting possibility that LC-mediated PPI deficits are transduced through a novel DA- and 5-HT2independent pathway that may operate in parallel to previously characterized substrates of PPI. The notion of parallel monoaminergic mechanisms for PPI has been suggested previously by systemic pharmacological studies using agonists and antagonists for DA and NE (Bakshi and Geyer, 1997; Carasso et al, 1998; Swerdlow et al, 2006), but the present studies for the first time implicate a specific neuroanatomical substrate in this dissociation.

Moreover, these findings significantly expand the understanding of the functional role of the LC in regulating behaviors that are pertinent to psychopathology. The manner in which LC regulates cognitive function is based on a complex set of dynamics between tonic and phasic neuronal discharge rates and electrotonic coupling of LC neurons (Aston-Jones and Cohen, 2005). Briefly, on the basis of observations of the firing patterns of LC neurons, an inverted U-shaped profile has been proposed for the regulation of cognitive performance by LC activity, with either hypo- or hyperactivity of tonic LC neuronal activity disrupting the ability to maintain focused attention (AstonJones and Cohen, 2005; Berridge and Waterhouse, 2003; Foote et al, 1980). This profile also mirrors the manner in which NE transmission in prefrontal cortex (presumably regulated by LC neuronal firing patterns) has been proposed to mediate working memory (Robbins and Arnsten, 2009). Moderate levels of tonic LC-NE discharge rates are associated with optimal performance, putatively by allowing for an enhanced 'signal-to-noise' ratio via increased phasic discharge of LC neurons, which promotes focused attention in the processing of salient information. Recent findings in humans corroborate this model by indicating that pharmacologically induced shifts of LC neuronal activity into a low-tonic mode is associated with enhanced cognitive performance (Minzenberg et al, 2008). High tonic LC-NE discharge rates, however, are associated with poor performance on selective-attention tasks due to 'attentional lability', associated with increased 'scanning' of the environment in an attempt to simultaneously attend to multiple stimuli (Aston-Jones and Cohen, 2005; Berridge and Waterhouse, 2003; Foote et al, 1980). Given the conceptualization of sensorimotor gating as a mechanism that defends higher order cognitive processes by filtering out potentially intrusive irrelevant stimuli (Braff et al, 2008; Geyer, 2008; Swerdlow et al, 2008), deficient sensorimotor gating (indexed by PPI) could also arise from tonic hyperactivity of the LC-NE system. Because the current peri-LC BET and AMPA infusion parameters reliably increase tonic LC firing (Berridge and Foote, 1991) and disrupt PPI, whereas clonidine reduces tonic LC firing (Berridge et al, 1993) and normalizes BET-induced PPI deficits, the present results provide the first clear evidence for this hypothesis. LC-NE is also well known to regulate sensory signal processing, with enhanced NE transmission having the ability to improve signal-to-noise characteristics of sensory receptive fields in a number of modalities and sites (Devilbiss and Waterhouse, 2004, 2011; Escanilla et al, 2010; Hirata et al, 2006; Hurley et al, 2004; Moxon et al, 2007). LC-NE effects on sensory signal processing also seem to follow an inverted-U-shaped profile, raising the intriguing possibility that high levels of tonic LC-NE activation (as would be achieved with the pharmacological approaches of the present studies) might affect the processing of the prepulse in primary sensory pathways as that information is conveyed to the pontine nuclei that ultimately mediate PPI. Such altered sensory signal processing of the prepulse could 
therefore potentially change how strongly these pontine sites are recruited by the prepulse to inhibit startle responses to the pulse.

There are few behavioral studies of direct pharmacological stimulation of LC in unanaesthetized rodents, particularly in a paradigm with clinical translational potential, thus, the present findings significantly expand our understanding of the functional role of the LC by providing a detailed characterization of the behavioral sequelae of acutely increasing LC activity in awake, behaving rats. The behavioral effects of this manipulation were remarkably selective and specific for sensorimotor gating rather than producing a generalized behavioral activation, in agreement with the seminal findings of Aston-Jones and Bloom (1981) and Foote et al (1980) that the LC regulates selective attention, and demonstrating for the first time that the LC also participates in the regulation of pre-attentional/ preconscious forms of information processing. These sensorimotor gating deficits could in fact contribute to the impairments in selective attention under conditions of high tonic LC activity.

Schizophrenia, Tourette's syndrome, and post-traumatic stress disorder (PTSD) have been associated with both deficient PPI and NE system dysfunction (Braff et al, 2008; Geyer, 2008; Swerdlow et al, 2008). Elevated NE and metabolites have been found in the cerebrospinal fluid, plasma, or brain tissue of schizophrenia patients (Yamamoto and Hornykiewicz, 2004), the cerebrospinal fluid of Tourette's (Leckman et al, 1995) and PTSD patients (Geracioti et al, 2001), and abnormalities in the LC itself also have been reported in schizophrenia patients (Gay et al, 1989; Lohr and Jeste, 1988; Marner et al, 2005). Because the present findings indicate that pharmacological stimulation of the LC-NE pathway is sufficient to disrupt PPI and dysregulation of the LC-NE system has been implicated in all of these conditions (Boehnlein and Kinzie, 2007; Robbins and Arnsten, 2009; Yamamoto and Hornykiewicz, 2004), it may be that altered tonic LC activity is a mechanism for the deficient sensorimotor gating that is seen in a subset of patients, regardless of their nosological classification into various illnesses. Drugs like prazosin, cataprese, olanzapine, and seroquel, that successfully treat these individuals may in part, derive their efficacy from normalizing the sequelae of LC-NE hyperactivity. Of course, LC-NE activation is not obligatory for all PPI deficits, and it remains to be determined to what extent deficient PPI maps onto clinically observed symptoms in these illnesses. Nevertheless, the present studies clearly indicate a novel $\mathrm{NE}$ substrate through which PPI can be compromised, and also demonstrate the sensitivity of this substrate to a number of different psychotropic medications, suggesting that these findings may have considerable clinical relevance.

There are several output structures through which LC could modulate PPI. One candidate is the pedunculopontine nucleus (PPTg), which mediates PPI by a direct inhibitory projection to the primary startle circuit (Fendt et al, 2001; Swerdlow et al, 2001; Swerdlow et al, 2008). The LC projects to the PPTg and under conditions of high NE release such as what might occur with pharmacological stimulation of LC, can inhibit the PPTg (Nakano, 2000). Thus, chemical activation of LC could inhibit PPTg and presumably remove the inhibitory effect of the prepulse on the startle circuit, thereby producing a deficit in PPI. In addition, LC sends projections to forebrain regions such as the prefrontal cortex, hippocampus, and amygdala (Berridge and Waterhouse, 2003) that are known to modulate PPI (Swerdlow et al, 2008), presumably in connection with higher order cognitive and motivational processing. Indeed, our recent work shows that direct stimulation of $\alpha 1 / \beta \mathrm{NE}$ receptors in multiple forebrain LC terminal fields disrupts PPI (Alsene et al, 2011). Thus, LC is positioned to affect PPI both directly and indirectly, through novel pathways that may function independently of DA and 5-HT2 receptors. In conclusion, these studies present evidence for a neural circuit originating in the LC and involving postsynaptic $\alpha 1$ $\mathrm{NE}$ receptors in the regulation of sensorimotor gating. Given the wide array of psychiatric illnesses with manifested PPI deficits, these findings suggest a new functional role for the LC in psychopathology.

\section{ACKNOWLEDGEMENTS}

We thank Marcia Ramaker, Ben Zahasky, and Liesl Schwerin for technical assistance, Dr Craig Berridge for helpful discussions and insights regarding LC neuronal activity following peri-LC infusions, and Astra-Zeneca for their donation of seroquel. R01-MH075980 (VPB) funded this work, and KMA was supported by F31-MH077465 and T32-GM007507.

\section{DISCLOSURE}

The authors declare no conflict of interest.

\section{REFERENCES}

Alsene KM, Carasso BS, Connors EE, Bakshi VP (2006). Disruption of prepulse inhibition after stimulation of central but not peripheral alpha-1 adrenergic receptors. Neuropsychopharmacology 31: 2150-2161.

Alsene KM, Fallace K, Bakshi VP (2010). Ventral striatal noradrenergic mechanisms contribute to sensorimotor gating deficits induced by amphetamine. Neuropsychopharmacology 35: 2346-2356.

Alsene KM, Rajbhandari AK, Ramaker MJ, Bakshi VP (2011). Discrete forebrain neuronal networks supporting noradrenergic regulation of sensorimotor gating. Neuropsychopharmacology 36: 1003-1014.

Aston-Jones G, Bloom FE (1981). Norepinephrine-containing locus coeruleus neurons in behaving rats exhibit pronounced responses to non-noxious environmental stimuli. J Neurosci 1: 887-900.

Aston-Jones G, Cohen JD (2005). Adaptive gain and the role of the locus coeruleus-norepinephrine system in optimal performance. J Comp Neurol 493: 99-110.

Bakshi VP, Geyer MA (1995). Antagonism of phencyclidineinduced deficits in prepulse inhibition by the putative atypical antipsychotic olanzapine. Psychopharmacology (Berl) 122: 198-201.

Bakshi VP, Geyer MA (1997). Phencyclidine-induced deficits in prepulse inhibition of startle are blocked by prazosin, an alpha-1 noradrenergic antagonist. J Pharmacol Exp Ther 283: 666-674.

Berridge CW, Abercrombie ED (1999). Relationship between locus coeruleus discharge rates and rates of norepinephrine release within neocortex as assessed by in vivo microdialysis. Neuroscience 93: 1263-1270. 
Berridge CW, Foote SL (1991). Effects of locus coeruleus activation on electroencephalographic activity in neocortex and hippocampus. J Neurosci 11: 3135-3145.

Berridge CW, Page ME, Valentino RJ, Foote SL (1993). Effects of locus coeruleus inactivation on electroencephalographic activity in neocortex and hippocampus. Neuroscience 55: 381-393.

Berridge CW, Waterhouse BD (2003). The locus coeruleusnoradrenergic system: modulation of behavioral state and state-dependent cognitive processes. Brain Res Brain Res Rev 42: 33-84.

Boehnlein JK, Kinzie JD (2007). Pharmacologic reduction of CNS noradrenergic activity in PTSD: the case for clonidine and prazosin. J Psychiatr Pract 13: 72-78.

Braff DL, Greenwood TA, Swerdlow NR, Light GA, Schork NJ (2008). Advances in endophenotyping schizophrenia. World Psychiatry 7: 11-18.

Bymaster F, Perry KW, Nelson DL, Wong DT, Rasmussen K, Moore NA. et al (1999). Olanzapine: a basic science update. $\mathrm{Br} J$ Psychiatry (Suppl 37); 36-40.

Bymaster FP, Hemrick-Luecke SK, Perry KW, Fuller RW (1996). Neurochemical evidence for antagonism by olanzapine of dopamine, serotonin, alpha 1-adrenergic and muscarinic receptors in vivo in rats. Psychopharmacology (Berl) 124: 87-94.

Carasso BS, Bakshi VP, Geyer MA (1998). Disruption in prepulse inhibition after alpha-1 adrenoceptor stimulation in rats. Neuropharmacology 37: 401-404.

Dawe GS, Huff KD, Vandergriff JL, Sharp T, O’Neill MJ, Rasmussen $\mathrm{K}$ (2001). Olanzapine activates the rat locus coeruleus: in vivo electrophysiology and c-Fos immunoreactivity. Biol Psychiatry 50: 510-520.

Devilbiss DM, Waterhouse BD (2004). The effects of tonic locus ceruleus output on sensory-evoked responses of ventral posterior medial thalamic and barrel field cortical neurons in the awake rat. J Neurosci 24: 10773-10785.

Devilbiss DM, Waterhouse BD (2011). Phasic and tonic patterns of locus coeruleus output differentially modulate sensory network function in the awake rat. J Neurophysiol 105: 69-87.

Escanilla O, Arrellanos A, Karnow A, Ennis M, Linster C (2010). Noradrenergic modulation of behavioral odor detection and discrimination thresholds in the olfactory bulb. Eur J Neurosci 32: $458-468$.

Fendt M, Li L, Yeomans JS (2001). Brain stem circuits mediating prepulse inhibition of the startle reflex. Psychopharmacology (Berl) 156: 216-224.

Foote SL, Aston-Jones G, Bloom FE (1980). Impulse activity of locus coeruleus neurons in awake rats and monkeys is a function of sensory stimulation and arousal. Proc Natl Acad Sci USA 77: 3033-3037.

Gay N, Cottraux JA, Denoroy L, Tommasi M, Kopp N (1989). Possible increase of dopamine-beta-hydroxylase activity in the locus ceruleus of paranoid schizophrenic patients: a preliminary post-mortem study. Psychiatry Res 27: 31-38.

Geracioti Jr TD, Baker DG, Ekhator NN, West SA, Hill KK, Bruce $\mathrm{AB}$ et al (2001). CSF norepinephrine concentrations in posttraumatic stress disorder. Am J Psychiatry 158: 1227-1230.

Geyer MA (2008). Developing translational animal models for symptoms of schizophrenia or bipolar mania. Neurotox Res 14: 71-78.

Geyer MA, Krebs-Thomson K, Braff DL, Swerdlow NR (2001). Pharmacological studies of prepulse inhibition models of sensorimotor gating deficits in schizophrenia: a decade in review. Psychopharmacology 156: 117-154.

Geyer MA, Swerdlow NR, Mansbach RS, Braff DL (1990). Startle response models of sensorimotor gating and habituation deficits in schizophrenia. Brain Res Bull 25: 485-498.
Gould TJ, Rukstalis M, Lewis MC (2005). Atomoxetine and nicotine enhance prepulse inhibition of acoustic startle in C57BL/6 mice. Neurosci Lett 377: 85-90.

Hirata A, Aguilar J, Castro-Alamancos MA (2006). Noradrenergic activation amplifies bottom-up and top-down signal-to-noise ratios in sensory thalamus. J Neurosci 26: 4426-4436.

Hurley LM, Devilbiss DM, Waterhouse BD (2004). A matter of focus: monoaminergic modulation of stimulus coding in mammalian sensory networks. Curr Opin Neurobiol 14: 488-495.

Jacobs BL, Abercrombie ED, Fornal CA, Levine ES, Morilak DA, Stafford IL (1991). Single-unit and physiological analyses of brain norepinephrine function in behaving animals. Prog Brain Res 88: 159-165.

Kamath A, Al-Khairi I, Bhardwaj S, Srivastava LK (2008). Enhanced alphal adrenergic sensitivity in sensorimotor gating deficits in neonatal ventral hippocampus-lesioned rats. Int $J$ Neuropsychopharmacol 11: 1-12.

Lahdesmaki J, Sallinen J, MacDonald E, Scheinin M (2004). Alpha2A-adrenoceptors are important modulators of the effects of D-amphetamine on startle reactivity and brain monoamines. Neuropsychopharmacology 29: 1282-1293.

Lapiz MD, Morilak DA (2006). Noradrenergic modulation of cognitive function in rat medial prefrontal cortex as measured by attentional set shifting capability. Neuroscience 137: 1039-1049.

Leckman JF, Goodman WK, Anderson GM, Riddle MA, Chappell PB, McSwiggan-Hardin MT et al (1995). Cerebrospinal fluid biogenic amines in obsessive compulsive disorder, Tourette's syndrome, and healthy controls. Neuropsychopharmacology 12: 73-86.

Lohr JB, Jeste DV (1988). Locus ceruleus morphometry in aging and schizophrenia. Acta Psychiatr Scand 77: 689-697.

Mansbach RS, Geyer MA, Braff DL (1988). Dopaminergic stimulation disrupts sensorimotor gating in the rat. Psychopharmacology (Berl) 94: 507-514.

Marner L, Soborg C, Pakkenberg B (2005). Increased volume of the pigmented neurons in the locus coeruleus of schizophrenic subjects: a stereological study. J Psychiatr Res 39: 337-345.

Minzenberg MJ, Watrous AJ, Yoon JH, Ursu S, Carter CS (2008). Modafinil shifts human locus coeruleus to low-tonic, high-phasic activity during functional MRI. Science 322: 1700-1702.

Mishima K, Tanoue A, Tsuda M, Hasebe N, Fukue Y, Egashira N et al (2004). Characteristics of behavioral abnormalities in alpha1d-adrenoceptors deficient mice. Behav Brain Res 152: 365-373.

Moxon KA, Devilbiss DM, Chapin JK, Waterhouse BD (2007). Influence of norepinephrine on somatosensory neuronal responses in the rat thalamus: a combined modeling and in vivo multi-channel, multi-neuron recording study. Brain Res 1147: $105-123$.

Nakano K (2000). Neural circuits and topographic organization of the basal ganglia and related regions. Brain Dev 22(Suppl 1): S5-16.

Oranje B, Kahn RS, Kemner C, Verbaten MN (2004). Modulating sensorimotor gating in healthy volunteers: the effects of desipramine and haloperidol. Psychiatry Res 127: 195-205.

Paxinos G, Watson C (1998). The Rat Brain in Stereotaxic Coordinates. Academic Press: San Diego.

Phillips MA, Langley RW, Bradshaw CM, Szabadi E (2000). The effects of some antidepressant drugs on prepulse inhibition of the acoustic startle (eyeblink) response and the N1/P2 auditory evoked response in man. J Psychopharmacol 14: 40-45.

Pouzet B, Andersen MP, Hogg S (2005). Effects of acute treatment with antidepressant drugs on sensorimotor gating deficits in rats. Psychopharmacology (Berl) 178: 9-16.

Pudovkina OL, Cremers TI, Westerink BH (2002). The interaction between the locus coeruleus and dorsal raphe nucleus studied with dual-probe microdialysis. Eur J Pharmacol 445: 37-42. 
Pudovkina OL, Kawahara Y, de Vries J, Westerink BH (2001). The release of noradrenaline in the locus coeruleus and prefrontal cortex studied with dual-probe microdialysis. Brain Res 906: 38-45.

Quednow BB, Kuhn KU, Stelzenmuelle R, Hoenig K, Maier W, Wagner M (2004). Effects of serotonergic and noradrenergic antidepressants on auditory startle response in patients with major depression. Psychopharmacology (Berl) 175: 399-406.

Ramirez OA, Wang RY (1986). Locus coeruleus norepinephrinecontaining neurons: effects produced by acute and subchronic treatment with antipsychotic drugs and amphetamine. Brain Res 362: 165-170.

Robbins TW, Arnsten AF (2009). The neuropsychopharmacology of fronto-executive function: monoaminergic modulation. Annu Rev Neurosci 32: 267-287.

Sallinen J, Haapalinna A, Viitamaa T, Kobilka BK, Scheinin M (1998). Adrenergic alpha2C-receptors modulate the acoustic startle reflex, prepulse inhibition, and aggression in mice. J Neurosci 18: 3035-3042.

Sara SJ (2009). The locus coeruleus and noradrenergic modulation of cognition. Nat Rev Neurosci 10: 211-223.

Schotte A, Janssen PF, Gommeren W, Luyten WH, Van Gompel P, Lesage AS et al (1996). Risperidone compared with new and reference antipsychotic drugs: in vitro and in vivo receptor binding. Psychopharmacology (Berl) 124: 57-73.
Svensson TH (2003). Alpha-adrenoceptor modulation hypothesis of antipsychotic atypicality. Prog Neuropsychopharmacol Biol Psychiatry 27: 1145-1158.

Swerdlow NR, Bakshi V, Geyer MA (1996). Seroquel restores sensorimotor gating in phencyclidine-treated rats. J Pharmacol Exp Ther 279: 1290-1299.

Swerdlow NR, Bongiovanni MJ, Tochen L, Shoemaker JM (2006). Separable noradrenergic and dopaminergic regulation of prepulse inhibition in rats: implications for predictive validity and Tourette Syndrome. Psychopharmacology (Berl) 186: 246-254.

Swerdlow NR, Geyer MA, Braff DL (2001). Neural circuit regulation of prepulse inhibition of startle in the rat: current knowledge and future challenges. Psychopharmacology (Berl) 156: 194-215.

Swerdlow NR, Weber M, Qu Y, Light GA, Braff DL (2008). Realistic expectations of prepulse inhibition in translational models for schizophrenia research. Psychopharmacology (Berl) 199: 331-388.

Valentino RJ, Foote SL, Page ME (1993). The locus coeruleus as a site for integrating corticotropin-releasing factor and noradrenergic mediation of stress responses. Ann NY Acad Sci 697: 173-188.

Van Gaalen M, Kawahara H, Kawahara Y, Westerink BH (1997). The locus coeruleus noradrenergic system in the rat brain studied by dual-probe microdialysis. Brain Res 763: 56-62.

Yamamoto K, Hornykiewicz O (2004). Proposal for a noradrenaline hypothesis of schizophrenia. Prog Neuropsychopharmacol Biol Psychiatry 28: 913-922. 